Article

\title{
Social Engagement among Migrant Youth: Attitudes and Meanings
}

\author{
Liudmila Kirpitchenko * and Fethi Mansouri \\ Centre for Citizenship and Globalisation, School of Humanities and Social Sciences, Deakin University, Burwood, \\ VIC 3125, Australia; E-Mails: liudmila.k@deakin.edu.au (L.K.), fethi.mansouri@deakin.edu.au (F.M.); \\ Tel.: +61-3-92443914 (L.K.); Fax: +61-3-92446755 (L.K.) \\ * Corresponding author
}

Submitted: 31 August 2013 | In Revised Form: 19 April 2014 | Accepted: 2 May 2014 | Published: 20 August 2014

\begin{abstract}
This article explores migrant young people's engagement, participation and involvement in socially meaningful activities, events and experiences. This type of social participation is approached in the social inclusion literature using the notions of social capital and active citizenship (Bourdieu, 1986; Coleman, 1988; Putnam, 1993; Putnam, 2000). A key objective, therefore, is to explore the attitudes, values and perceptions associated with social participation for young people. They include the meanings that social engagement has for migrant young people, along with drivers and inhibitions to active participation. The article focuses on both the motives for being actively engaged as well as perceived barriers to social engagement. It is based on a large study conducted among migrant young people of African, Arabicspeaking and Pacific Islander backgrounds in Melbourne and Brisbane, and presents both quantitative and qualitative (discursive) snapshots from the overall findings, based on interviews and focus groups. While many studies have centred on the management of migration and migrants, this article draws attention to the individuals' active position in negotiating, interpreting and appropriating the conditions of social inclusion. Accounting for the multidimensional and multilayered nature of social inclusion, the paper highlights the heuristic role of social engagement in fostering the feelings of belonging and personal growth for migrant youth.
\end{abstract}

\section{Keywords}

active citizenship; belonging; civic engagement; intercultural relations; migrant youth; motivations for participation; social capital; social networks

\section{Issue}

This article is part of the special issue "Migrant Youth, Intercultural Relations and the Challenges of Social Inclusion", edited by Professor Fethi Mansouri (Deakin University, Australia) and Dr. Anna Halafoff (Deakin University, Australia).

(C) 2014 by the authors; licensee Cogitatio (Lisbon, Portugal). This article is licensed under a Creative Commons Attribution 4.0 International License (CC BY).

\section{Introduction}

In recent scholarship on ethnicity and migration, there has been renewed interest in the notions of social inclusion, social engagement and social cohesion, perceived as an alternative to the previously dominant focus on social conflict and related notions of racism, discrimination, marginalisation and alienation. Both terms, social inclusion and social exclusion, first began to enter public discourse in France in the 1970s. The terms spread to the rest of Europe in the 1980s and 1990s, becoming a particular policy concern of the UK
Government in 1997 (Saunders, 2005). Their entry into Australian public discourse has been recent by comparison. With the election of the Labor Government in November 2007, addressing social issues via social inclusion initiatives promised to play a prominent role in public policy development in Australia (Gray \& Hayes, 2008). It is notable that the terms social inclusion and social exclusion were used in the social sciences scholarship to expand the discussion beyond poverty and economic disadvantage by accounting for the complex relations between the individual and the society (Fangen, 2010). One of the pioneers of this focus in the 
social sciences was Room (2004) who conceptualised social exclusion as a multi-dimensional form of disadvantage, which included aspects of material and nonmaterial exclusion.

Room and others have been central to the development of a new "social exclusion" perspective, which is designed to account for the heterogeneous, multicultural and complex reality of contemporary social relations. This new perspective stresses a variety of sociodemographic and socio-cultural variables that contribute to social exclusion, and looks at their complex interaction instead of focusing on separate demographic variables like education and income. Hunter (2009) introduced the notion of "cumulative or circular causation" in explaining the cycles of social exclusion, as interrelationships between the various dimensions of disadvantage (employment, income, education) are complex and tend to be mutually reinforcing. In the last two decades, social exclusion discourses have moved beyond recognition of "class" as the primary driver of disadvantage, with ethnicity and migration status becoming "totally new focuses in the research on social exclusion" (Fangen, 2010, p. 134). Modood's (2013) work is an example of this interactionist perspective, which focuses on the intersectionality of variables such as ethnicity, gender and class background to explain social exclusion.

As a companion concept to analyses of social exclusion, "social inclusion" proved to be a fertile platform for addressing diverse issues related to social inequality. Social inclusion effectively acquired various terms and interpretations. For example, Ulf Hedetoft (2013, p. 1) suggests in the inaugural editorial article of this Journal that social inclusion includes such notions as "social inclusiveness, cultural cohesion, communal values, a shared identity, mutual recognition, respectful dialogue, peaceful interaction, policies of integration". Another example for analysing the complexities of social inclusion is suggested by Freiler (2002) who identified five critical dimensions of social inclusion that are particularly relevant to migrant youth. They include: valued recognition, human development, involvement and engagement, proximity, and material wellbeing.

Acknowledging the multidimensional and multilayered nature of social inclusion this article seeks to highlight the role of social engagement in fostering feelings of belonging and personal growth for migrant young people. First, the paper reviews theoretical considerations describing the notions of social engagement and social capital and how they are of special relevance to migrant youth. Second, it discusses the motivating aspects of social engagement and looks at the incentives which underlie young people's increased engagement, including resultant feelings of belonging, security, community, and support; as well as getting service or help; meeting people with similar interests and backgrounds; and building friendships. The article concludes with an analysis of meanings attached to civic participation and social engagement among migrant youth, including feelings of empowerment, identity building, abilities to defend human rights, promote social justice and social equality, and opportunities for personal development.

\section{Social Engagement and Migrant Youth}

The notion of social capital, broadly defined as available social networks, has a strong scholarly tradition (Bourdieu, 1986; Coleman, 1988; Putnam, 1993; Putnam, 2000). This paper takes into account the fundamental premise of the social capital literature, namely, that strong engagement in societal networks generally correlates positively with a range of favourable social, health and attitudinal outcomes (Vyncke et al., 2013; Woolcock, 1998; Portes, 2000; Putnam, 2007). As the literature shows, migrant experiences in general are fluid since migrants resettling in a new country have to establish new social ties by taking part in the social networks of a new country. The identities of migrant young people are particularly fluid, owing to their life stage; adolescents in the process of formation are foremost susceptible to the influences of their networks. Kroger (2004, p. 208) has analysed five theoretical streams in studies of adolescence and youth that identify adolescence as a "time of heightened activity for most in the loss and creation of new balances". For the current generation of young people, and migrant youth in particular, these ordinary negotiations of identity are more challenging, as young people have grown up in the period when neoliberal policies tied to individualisation, accompanied by a retreat from multiculturalism, have become pronounced at the political level and echoed in everyday media discourse (Portes, 1998; Harris, 2013). In these political conditions, young migrant people represent an optimal group for exploring the impact of the practices of social engagement on their wellbeing and sense of belonging.

Younger people are in a particularly vulnerable position because not all social networks have a positive effect and some may have a distinctly negative impact. Some negative consequences of social capital may include "exclusion of outsiders, excess claims on group members, restrictions on individual freedoms, and downward levelling norms" (Portes, 1998, p. 15). Of foremost concern to Australian public policy makers are "situations in which group solidarity is cemented by a common experience of adversity and opposition to mainstream society" (Portes, 1998, p. 17). Especially following the 2005 Cronulla riots in Australia, young migrant groups have been linked to socially divergent behaviour and marginalised activities. As Harris (2013, p. 3) points out: "Youth-driven civil unrest, terrorist attacks and the visibility of large and youthful immigrant population in global cities have become constructed as 
interrelated problems that call into question the sustainability of diversity and the future of the nation as we know it".

This paper is interested in exploring culture-specific networks that provide an important and positive resource in negotiating adjustment to a new country, particularly in the settlement stage (Hagan, 1998; ColicPeisker, 2005), while acknowledging that their effect may also be negative if networks become too restrictive and lead to ghettoization (Hardwick, 2003) or the promotion of radical agendas (Tilly, 2007). The current generation of multicultural youth have been particularly subjected to problematizing and marginalizing discourses by the majority culture (Triandafyllidou, 2006). For example, migrant youth in Australia have been described as "prone to inter-ethnic conflict, lacking intercultural awareness, in need of values education, dissociated from participatory life and disruptive to community harmony" (Harris, 2013, p. 141). In addition, young migrant people have become a "target of anxiety about national security, social cohesion and the future of culturally diverse nations" (Harris, 2013, p. 141).

Despite the abundance of literature on social capital and social networks, there is a dearth of sociologically informed understanding on the significance of social networks for fostering feelings of belonging and personal growth for migrant youth. Active positions of migrant youth in negotiating social engagement and participation have rarely become a focus of the research. Harris (2013, p. 5) writes that young migrant people "are rarely seen as civic actors, creative agents or multicultural citizens in their own right, and the complex realities of their everyday experiences of living in multicultural environments have been over-looked". This paper endeavours to respond to this call and examine active stances, self-perceptions and attitudes that young people associate with participating and belonging to social networks. In approaching migrant youth as active creative agents, this article finds very relevant the term "self-Actualizing Citizens", which was coined by Bennett (2003). Self-actualising citizens describe people who are actively and "self-reflexively" involved in personally meaningful and shifting social networks.

\section{Methodology}

The paper is based on both statistical and narrative research findings of a large study conducted among migrant youth in 2011-2012. Migrant youth were selected among three broadly clustered ethno-cultural groups: Arabic-speaking, Pacific Islander and African. These groups were chosen for participation because they are arguably among the most vulnerable and marginalised in Australia. Their vulnerability has been seen in recent high-profile cases linking them to the manifestations of prejudice, stigmatisation, racism, public disorder and inter-communal conflict. A quantitative survey included 484 young people, aged 15 to 23, in Brisbane and Melbourne, Australia. Young people included in the project had varying lengths of Australian residency and migration pathways, spoke a variety of languages and had varying levels of intergroup and intragroup social participation. See Table 1 below for a summary of the main demographic characteristics of the survey sample.

Table 1. Survey Sample at a Glance.

\begin{tabular}{|c|c|c|c|c|c|}
\hline $\begin{array}{l}\text { Participant } \\
\text { Groups }\end{array}$ & Age & Gender & $\begin{array}{l}\text { Three Top } \\
\text { Countries of } \\
\text { Birth }\end{array}$ & $\begin{array}{l}\text { Length of } \\
\text { Residence in } \\
\text { Australia }\end{array}$ & Religion \\
\hline African & $\begin{array}{l}15-17 \text { y/o: } 42.2 \% \\
18>: 56.6 \%\end{array}$ & $\begin{array}{l}\text { Male: } 49.4 \% \\
\text { Female: } 50.6 \%\end{array}$ & $\begin{array}{l}\text { Sudan: } 46 \% \\
\text { Ethiopia: } 14.3 \% \\
\text { Kenya: } 6.6 \%\end{array}$ & $\begin{array}{l}<5 \text { yrs: } 50.6 \% \\
6-10 \text { yrs: } 34.9 \% \\
11>\text { yrs: } 9.0 \% \\
\text { Australian born: } \\
3.0 \%\end{array}$ & $\begin{array}{l}\text { Christian: } 74.9 \% \\
\text { Muslim: } 15.0 \%\end{array}$ \\
\hline Pacific Islanders & $\begin{array}{l}15-17 \text { y/o: } 46.4 \% \\
18>: 53 \%\end{array}$ & $\begin{array}{l}\text { Male: } 42,4 \% \\
\text { Female: } 57.6 \%\end{array}$ & $\begin{array}{l}\text { New Zealand: } \\
42.4 \% \\
\text { Australia: } 40.4 \% \\
\text { Samoa: } 9.8 \%\end{array}$ & $\begin{array}{l}<5 \text { yrs: } 15.9 \% \\
6-10 \text { yrs: } 15.2 \% \\
11>\text { yrs: } 27.2 \% \\
\text { Australian born: } \\
39.7 \%\end{array}$ & Christian: $94.7 \%$ \\
\hline Arabic-speaking & $\begin{array}{l}15-17 \text { y/o: } 39.4 \% \\
18>: 60.6 \%\end{array}$ & $\begin{array}{l}\text { Male: } 47.9 \% \\
\text { Female: } 52.1 \%\end{array}$ & $\begin{array}{l}\text { Australia: } 50.6 \% \\
\text { Iraq: } 22.9 \% \\
\text { Lebanon: } 6.6 \%\end{array}$ & $\begin{array}{l}<5 \text { yrs: } 20.0 \% \\
6-10 \text { yrs: } 15.2 \% \\
11>\text { yrs: } 12.7 \% \\
\text { Australian born: } \\
50.3 \%\end{array}$ & $\begin{array}{l}\text { Muslim: } 64.5 \% \\
\text { Christian: } 32.5 \%\end{array}$ \\
\hline
\end{tabular}


With the help of the partner multicultural community organisations, fifty-seven interviews were conducted in Melbourne and forty-six interviews in Brisbane. Across both sites, there was a fairly even distribution of each ethno-cultural participant group. In addition, approximately thirty individuals (from all three participant groups) joined focus groups organised in two cities in 2011.

\section{Empirical Insights: Positive Externalities of Social Connections}

Young people were surveyed about the positive outcomes of having social connections with people (e.g., family, friends, neighbours, groups and associations). After analysing multiple responses, three categories were created that were coded as follows: (1) feelings of security, community, support; (2) getting a specific service or help; (3) meeting people with similar interests and backgrounds and creating friendships.

\subsection{Feelings of Security, Community, Support and Getting Help}

Connections with people provided "feelings of security, community, support" - it was a particularly popular response, with 68.9 per cent of Africans, 72.8 per cent of Pacific Islanders; and 63.3 per cent of Arabic-speakers selecting this option. When answers were compared within two age groups-15-17 y/o and 18 years and over-stronger support for experiencing feelings of security, community, support were found among the older group for Africans (70.5 per cent versus 65.7 per cent for the younger group) and Arabic-speakers (67.3 per cent vs. 56.9 per cent), but Pacific Islanders reported the opposite. Thus, among Pacific Islanders, 75.7 per cent of the younger group (15-17 y/o) and 70.0 per cent of those who were $18 \mathrm{y} / \mathrm{o}$ and over said "yes". Gender did not have a profound effect on the responses to the question on perceiving "feelings of security, community, support" in all there groups. Within the African group, 73.8 per cent of females responded "yes" compared to 63.9 per cent of males. Among Pacific Islanders, 71.3 per cent females and 75.0 per cent males, and among the Arabic-speakers 60.9 per cent females and 65.8 per cent males agreed with this option.

Participants were asked whether they think they "get help to get things done" from the "different types of connections" they have with people. Negative responses to this question predominated among all three groups, thus 53.9 per cent of Africans and 50.3 per cent of Pacific Islanders said "no". The largest divergence however was reported among Arabic-speakers with 36.7 per cent saying "yes" and 63.3 per cent saying "no". A related option of getting a "specific service or help out of the connections" generated even more modest support: 18 per cent of African youth, 20.5 per cent of Arabic-speakers and 24.5 per cent Pacific Island young people confirmed that they received a specific service or help through their networks. Difference between genders was noted in all three groups in how much they thought that connections that they formed with people (their networks) can provide support or a specific help to them. In the African group, 21.4 per cent of females (compared to 14.5 per cent of males) and in the Pacific Island group, 29.7 per cent of females (compared to 20.7 per cent of males) were more likely to feel that they have received help. In the Arabicspeaking group, however, it was males ( 25.3 per cent) who perceived that they were more likely to have received service or help out of connections than females (16.1 per cent).

\subsection{Building Friendships, Meeting People with Similar Interests, Backgrounds}

Building "friendship" was a main desired goal of social connections for young respondents, with three out of four people of the overall sample selecting this option. Preference for gaining "friendship" (75.2 per cent) as a result of connections with people was followed by a "feeling of security" (68.2 per cent), and "meeting people with similar interests and backgrounds" (49.4 per cent). This latter option was more important for Pacific Islanders (62.9 per cent) than it was for the other two groups. All these elements of belonging were more keenly felt among the male participants across all three groups.

In the Pacific Island group, engagement in social networks was closely tied to young people's feelings of belonging within and beyond their own ethnic group. At various times, interviewees cited both desires for outward engagement (with others of non-Pacific Island backgrounds) and engagement with those from shared cultural backgrounds as a means to foster feelings of belonging across contexts. A female, 18, from Brisbane said:

It's that sense of belonging that makes you want to go back to those groups and form those groups. Everyone has that sort of intrinsic feeling to belong to a group of people that are there to support you and to go through life with you and the challenges and to help you out.

For the African group, the impact of network engagement on a sense of belonging was multi-dimensional and shaped by the network member composition. Interviews reveal that some young people embraced associations with other Africans while others rejected them entirely. As most African interviewees were relatively recent arrivals, networks were often composed of other refugees from similar backgrounds. These highly homogenous networks appeared to foster a 
strong sense of intra-group, ethnic belonging amongst interviewees. A female from Brisbane observed: "When I hear them speaking Ugandan I get a big smile, like 'oh my God, someone like me'. It feels so good". Thematic analysis indicates that the conflicting feelings were tied to fluctuating perceptions of intra- and inter-group belonging, specifically to perceptions of being "Australian" and living the "Australian way of life" (Melbourne Focus Group).

For those interviewees who participated in more ethnically or culturally diverse networks, the sense of belonging was linked with perceptions of being Australian. It meant that the more diverse their networks were, the more "happy" or "lucky" they perceived themselves to be. A female, 16, from Melbourne explained:

If I'm with my country people I don't feel very good or happy because we speak the same language, but if I'm with other people [...] people that come from different country, I feel good, happy to be with them [...] I'm not really good when I'm with my own people. I can't be really happy.

This participant along with the next spoke of their desire to be included in the heterogeneous social networks of a new country and the importance of this inclusion for their experiences and feelings of belonging. Another participant described how lucky he felt having "white friends" (people outside of his immediate circle) while being still new to the country:

I feel like I've been really lucky coz when I speak with [...] the African guys, some of them were born here and they are 20-19 (years old). [...] They say they don't have white friends. That shocks me. [...] And when they see that all my friends are all white, they say to me 'How you go with that?' 'Were you born here?' 'Did you go to high school here?' and I say 'No, I've been here for 15 months'. (Male, 20, Melbourne)

Similarly to African and Pacific Island interviewees, the Arabic-speaking group also experienced context specific types and levels of belonging. Within the Melbourne sample, Australian born interviewees or those with longer settlement duration were typically more engaged across diverse cultural and ethnic groupings and felt belonging both within and beyond their ethnic communities. For the recent arrivals and younger Arabic-speaking interviewees, engagement in family- or ethno-specific networks appeared to be the context in which their belonging was sought and cultivated. A female, 16, from Melbourne said she felt more understood within her cultural group: "Because it effects, because they are from the same culture, so my family, and some of my friends, so they understand me more".
Another female, 16, from Melbourne described her bond with her family: "I feel like they like me, I like to always be with them. Yeah, like I belong to somewhere".

Arabic-speaking participants negotiated their sense of belonging across multiple places, ethnicities and cultures on a daily basis. Sometimes they felt a sense of attachment to their multicultural or hybrid selves and expressed support for heterogeneous, multicultural Australia. At other times, sense of belonging was closely tied to one of the elements of their identity. Among the Muslim interviewees in Brisbane, formal and informal networks centred almost exclusively on the mosque. As such, the belonging which network participation fostered was tied to being a Muslim. Amongst the Arabic-speaking interviewees, there was a strong sense that negotiating Australian belonging or identity for the Muslims, Arabs, and Middle Easterners was a daily task and one that was informed, but yet also changed, according to socio-cultural contexts.

Belonging within and across different networks was impacted by gender, religious affiliation and time lived in Australia. In the survey, 47.6 per cent of Arabicspeaking participants said that they had someone to rely on as a result of their network involvement. This increased with the length of residency in Australia: 42.4 per cent of those that were newly arrived; 44 per cent of those that had lived in Australia for 6-10 years; 52.4 per cent of those that had lived in Australia for 11 or more years; and 51.2 per cent of those that were born in Australia had someone to rely on as a result of their networks. Younger Arabic-speaking participants were more inclined to build friendships with people who are involved in their social networks. Making friends was an important outcome of network engagement for 81.5 per cent of aged 15-17, and 69.3 per cent of those aged 18 and over. Females (77.0 per cent) were more likely to have made friends through their networks than males (70.9 per cent).

\subsection{Intersections of Formal and Informal Networks}

Interviews and focus groups revealed that the involvement of young people in social networks across the three groups is characterized by a strong degree of intersection, mutual enforcement and cross-pollination between their formal and informal social networks. This interconnectedness was most apparent within the Pacific Islander youth group. Interviewees consistently reported a blending of different networks, from formal to informal and vice versa. For most interviewees, while network involvement was expansive, network members were predominantly limited to other Pacific Islanders. The researchers came across an interesting cross-cultural hip hop choir in Melbourne's West (Massive), in which a considerable number of Pacific Islanders were involved. The group is not limited to $\mathrm{Pa}$ cific Islanders, but includes a range of young people 
whose "sense of place" is an important element of their everyday lives and creative outlet. As one participant explained:

A large number of kids are coming together to rehearse. It's a good example how some of our Pacific Island leaders have stepped up and motivated everyone. And it hasn't been a massive campaign or anything like that. It's just people knowing that it's the place to be and respecting each other. [...] They promote respect for each other [...]. (Pacific Islander Focus Group, Melbourne)

Among the Pacific Islanders group, parents or other family members often cooperate in the formal networks, thus adding an informal level of interaction to their involvement in formal networks. For instance, a case of interviewees' involvement in a cross-sectional initiative called Pacific Pathways (Melbourne) presents a bridge between two types of networks and brings out the dialogical nature in young people's network participation. The reasons for a blurring divide between formal and informal networks may also be found in a set of different traditions, habits, and culturally and/or religiously based practices. Moreover, blending of the roles of the community leaders, religious leaders, family members and friends, was also noticeable. Overall, the Pacific Islander group presents distinctively rich material in terms of crossovers of formal and informal network activities for young people.

For African youth, the interconnectedness of networks was less prominent though still strongly noticeable. With the majority of African interviewees being relatively recent humanitarian arrivals, there was a strong dependence on service providers not only for practical settlement assistance, but also for network building. Several interviewees noted that it was through their formal involvement with service providers, that their informal networks (mainly friendships) were developed. As a young male from Brisbane explained:

Most of us we either play sports, we are good at it. Then we get into it and then be friends from there. Or music, you do the music then make friends together. Like you can't just go talk because you don't speak the language. So you have sports and music first, then making friends. Without having talking, it's through doing.

In an interview with a young African male who came to Australia on his own (without any family members) and spent the first seven months in an immigration detention, there was a noticeable transition from formal to informal type of networks even though they involved the same people. One of the interviewee's first contacts in Australia were people visiting immigration de- tention casually, but they were at first still perceived as more formal then informal connections. Later on, some of these visitors and volunteers became "good friends". A male from Melbourne called this circle of people his "family" as they helped him the most when settling in the new environment: "They helped me to learn English coz I didn't know even like job or study [...]. So I just got information, coz everything is new. Everything is new for me. The system is new, CentreLink, school, everything. Even crossing the road, everything is so different".

For the Muslim sub-group within the broader Arabic-speaking youth group, interviewees in Melbourne tended to participate in the activities targeted for all Arabs, rather than only for Muslims, as one participant explained:

The activities that I wouldn't join are [...] the Islamic activities [...]. Although it's my religion, but I just wouldn't join it. I would join Arab activities [...] anything to do with Arab, because it's general, it's all religions. But Muslim [...] I don't know what information they're going to give me. I wouldn't join a special religious activity, something to do with religion [...].

Another participant said: "Islamic society unfortunately represents Muslims born in Australia, I don't feel like they represent me who came later [...]". A third participant added: "So you just feel more out of place, because you are meant to relate to them, but you go there and you can't relate [...]" (Arabic-Speaking Focus Group, Melbourne).

In Brisbane, on the other hand, mosques served as a central venue for participants for creating formal and informal networks. Within the Muslim group, only one person mentioned non-mosque related networks (university and career related); for the vast majority of interviewees, all networks (even when raising money for nationwide initiatives, such as Cancer Cure) were organized and facilitated through mosques. When describing his experience in charitable activity, one male interviewee from Brisbane explained: "I've been part of the Muslim community and been called upon to join, so I did". Or, with regards to religious practices, a female from Brisbane said: "Normally I come here twice a week because on Fridays I come for Qur'an and on Sundays I come for Arabic. Then some people come on Saturdays and Fridays. Some people just come on Fridays".

In Melbourne, religious activities generally did not get such a strong support among interviewees and focus group participants who identified with either Christian or Muslim religions. Except of one interviewee who was teaching in an Islamic Sunday school, religion did not play a significant role in the networking or network participation. This interviewee engaged in a range 
of other social activities; but the majority of these were not connected to religion. This does not mean, however, that religion was not important to the personal lives of people who participated in this study. There was consistent support for going to church, mosque or another place of worship among all groups. Survey data showed that in Melbourne, 37.9 per cent of Africans, 44.4 per cent of Pacific Islanders, and 35.6 per cent of Arabic-speakers liked to go to places of worship. Their church or mosque attendance however was a more personal initiative or connected to their extended families. As a male participant in Melbourne explained: “That's where I can see all my relatives, and the people that I know [...]. And where I practice my culture". In most cases, church attendance did not extend to youth groups or associations that would be specifically tied to religious organizations. A female interviewee in Melbourne said: "Yeah my church has a youth group. [...] Usually their things are on a Saturday or a Sunday. I work Saturday and Sunday so it's too hard for me. So I'll just go whenever they have something".

Network change over time was mostly reported by African youth, the majority of whom had recently migrated on a humanitarian visa (both UNHCR and family sponsorships) and had very limited knowledge of English. Many African interviewees experienced diverse pre-migration situations, including protracted refugee camp stays, and therefore had significant settlement challenges. Consequently, much of early network involvement was limited to opportunities offered through service providers and family members (if available) and typically consisted of engagement with other African refugees. A female participant in Brisbane admitted: "You only keep to the people you know. I'm like you African, I'm African, you know like we should have that connection".

Indeed, qualitative analysis suggested a strong relationship between the period of settlement and the types of formal and informal networks in which young African's participated. A male interviewee in Brisbane said:

When I first got here, it was just me with Dinka people. Then the longer I am here, I slowly move out. The longer you're here, the more relaxed you get. But when you get here, you only be with the people that you are new with. You tend to stick with the people that you have common grounds with.

This excerpt illustrates that, as the duration of respondents' settlement increased, with arguably concurrent improvements in English language and settlement navigation competency, the types of networks in which young Africans participated underwent some positive transitions. Along with these improvements, interviewees also reported an increased mobility by us- ing public transport, which enabled them to participate in non-local as well as local networks. African young people reported gradual changes in the types of their networks. Despite this, many interviewees sustained engagement with earlier networks, including service provider networks.

Research data suggest that there are a number of factors impacting on network participation for African young people. They include: duration of settlement in the country, proficiency in English, and institutional competency. Most of the interviewees created social connections in the early periods following their arrival and many sustained engagement with early networks, including service provider networks. For some African young people networks changed drastically and this fact suggests the important role of period of settlement in the country as well as level of proficiency in English.

\section{Meanings of Social Engagement for Young People}

Although many programs exist for promoting social engagement of youth, the meanings of everyday intercultural interactions of young people are rarely examined and young people's interpretations of social engagement rarely become a focus for research. This research has specifically sought to probe the views of migrant young people as active agents of social engagement, rather than passive recipients of social initiatives and programs. Participants' motivations and the meanings attached to social engagement are at the centre of this research. Interviewees from all three communities expressed a clear desire for cross-cultural engagement, even if their current networks were predominantly ethno-specific. Among Africans and Pacific Islanders the interest in cross-cultural engagement was higher, with 55.4 per cent and 55.0 per cent saying "yes" and a further 37.3 per cent and 38.4 per cent saying "sometimes" in response to a statement "I like to be involved in activities happening outside of my family/ethnic group". Among Arabic-speaking youth the interest was lower, with only 34.3 per cent responding "yes" and 47.6 per cent responding "sometimes". Overall, there was a strong interest in reaching beyond their ethnic or religious communities and creating cross-cultural connections.

\subsection{Cross-Cultural Interactions and Identity Building}

Motivations for cross-cultural engagement and intercultural interactions somewhat differed for the groups surveyed. For Pacific Islander interviewees in particular, desire for cross-cultural engagement was often a reaction against perceived homogeneity or insularity of the formal and informal networks in which they were engaged, which were overwhelmingly composed of fellow Pacific Islander youth. Several young people re- 
ported that parents were not necessarily encouraging of cross-group interactions. Discussing a desire for multicultural network participation, one female interviewee from Brisbane noted: "We need to interact. If they [parents] listen to youth, get the opinion from youththat will mean more interactions with different cultures".

Pacific Islander interviewees also appeared curious about the goings-on within different cultures. When asked about why they craved cross-cultural engagement, one male interviewee from Brisbane explained: "Getting exposure to each other's different backgrounds [...] you know, food, music, just knowing about each other's different cultural backgrounds". Another female Pacific Islander interviewee from Melbourne mentioned how the sole exposure to cultural diversity makes one appreciate it and "become more multicultural":

I think if we had stayed in New Zealand, I would've only been hanging out with my kind of peoplePacific Islanders, [...] but we came here. With Melbourne being a multicultural city, I've learnt about different cultures, and gained understanding about them, and I think that's made me a better person.

An African Focus Group participant explained her initial decision to volunteer outside of her ethno-cultural group with the fact that she wanted to reach out to the broader community and create cross-cultural linkages:

In order to get other people interested in your cause you need to get up, because you all know that [...] 9/11 [...] the African community [...] yes we're black and were in refugee camps and hunger and starvation [...] but you need to let other people outside see that and personalise and humanise that experience.

A female participant of the Arabic-Speaking Focus Group was very supportive of the opportunities for these communities to have cross-cultural interactions:

I think it's a good idea to bring groups and communities together to achieve something. And it's always interesting, because you find the solutions together. You have the same problems and the same issues that you go through and you wouldn't think that.

Every ethno-cultural group included in this survey tended to have different perceptions of the intercultural processes contributing to their identity-building. For African interviewees, participation in multicultural networks appeared to represent a type of cultural competency, as though, the more multicultural their networks, the more strongly they felt that they be- longed in Australia. For the Arabic-speaking youth, participation in cross-cultural networks appeared less urgent, particularly in Brisbane. Several interviewees mentioned that cross-cultural engagement was perhaps a good way for others to learn about their culture, religion, etc., and a way to minimize or counter stereotypes and misconceptions. One interviewee reported engagement in cross-cultural networks through raising money for the aftermath of the Brisbane floods. Another male interviewee from Brisbane suggested: “I was thinking we could invite other religions to come and see each other, like for example invite churches to our mosque, like just to talk". Within the Melbourne sample, some interviewees appeared to participate in cross-cultural networks as a way to distance themselves for singularly "Muslim" or "Arab" networks. For some interviewees in this group, participation in multicultural, non-religious affiliated networks was perceived as important.

\subsection{Personal Development and Individual Responsibility}

Many participants perceived social connections and networks as contributing to their personal development. They also spoke about individual responsibility and initiative as the necessary components of successful engagement. An African participant of the focus group remarked: "I was the only black person doing at the University doing education. And [...] you have to jump on that opportunity and use it. How did Obama become a president?" He then went on:

If you're a young person you have an opportunity to educate yourself, to get somewhere. Then you'll recognise all these advantages that are out there [...]. If you're a smart person, you'll improve your life. In the life of my parents and of my community as a whole, I have to be a leader, be out there, talk about issues and do what I can do. And it's up to us.

Another African participant shared her thoughts on individual responsibility and self-motivation:

Most of young people complain and they do nothing about it, thinking that someone else will do things for you. And it's about the time to prove yourself [...]. And also changing yourself [...] you tune to the levels that could be a way of doing things. And this will help you.

An Australian-born 21 year-old female who identifies herself as a Palestinian, and whose family lives in Jordan, after mentioning her fears of facing discriminatory remarks at work, told us that it is nevertheless her responsibility to learn how to react to them in a positive way: 
I could help myself by being more confident and more upfront without thinking 'what if they?' Just [...] don't think 'it's going to be annoying here' [...] because you're going to find that everywhere [...] even if I wasn't wearing a scarf, I'm going to have people that don't like me anyway. So through my Islam I'll show them a good character of what we actually are, so they don't go thinking other things, so through my good character I'll show them: 'I am like you'.

These extended quotes above provide good examples of perceptions and attitudes that young people demonstrate in taking responsibility for actively constructing their identity and building positive cultural values and expectations. These participants all shared a sense of active engagement, or "agency", in constructing, negotiating and interpreting intercultural encounters.

\subsection{Sense of Empowerment}

Some participants saw their participation in the social networks as contributing to their sense of empowerment. An African youth explained that she had volunteered both within and outside her ethno-cultural group for over three years now. She viewed her continued participation in the matters of her community with a feeling of personal achievement:

When you wait around and say something, people will see potential in you. [...] People have to see what you do. People have to see how you are fond of things [...]. And you have to prove yourself to the community [...]. And the community has high expectations, especially the African community. (African Focus Group)

Similarly, a female Arabic-speaking participant described her volunteering experiences with a sense of accomplishment and personal growth:

I used to work in the community and I used to feel happier, because you feel like you achieved something. I used to work for a radio and I could deliver something, say something, people call and they say... oh, you have really good... or oh I like the music.

She also explained that her motivation is coming from within, since there is little support from her family or friends:

I don't find so much support from friends [...]. They are like: 'Why do you care about other people so much? Worry about your own problems'. [...] Friends [...] they don't want you to do that. [...] You need to believe in what you're doing. You need to satisfy your own self.
A sense of self-empowerment as well as a sense of active agency have been evident in these personal reflections.

\section{Conclusion}

This article explored social engagement by positioning young migrant people as active agents of social inclusion, rather than as passive recipients of a variety of government programs and initiatives. This research examined young migrant people's attitudes, values and perceptions associated with involvement in social networks; and the diverse ways young people negotiate social inclusion in their everyday lives. In doing so, it explored the meanings that social engagement carries for the migrant youth, along with the driving forces and inhibitions to participation. The findings suggest a view of the "self-Actualizing Citizen", which describes "selfactualizing" or "self-reflexive" involvement in personally meaningful and shifting social networks (Bennett, 2003).

This research provided evidence for approaching and conceptualising the social inclusion agenda as a positive shift from a previously prominent conflict perspective, also described as a "tolerance model" which highlighted poverty, unemployment and marginalised moral attitudes of migrant youth (Mansouri \& Lobo, 2011, p. 6). While within the "tolerance model" migrant youth tended to be negatively portrayed as "passive subjects" in need of being "managed and disciplined" (Mansouri \& Lobo, 2011, p. 6), the social inclusion model highlights a holistic approach to integration. This paper contributes to portraying social inclusion as a "transformative idea" that has a potential for challenging and redefining the society we live in (Levitas, 2003). What needs to be redefined is the society's approach to diversity and the social inclusion model calls for a "valuing of diversity, not just the recognition of diversity and difference. It recognizes that diversity and difference do possess their own worth-and are not challenges to be overcome" (Hanvey, 2003).

This article's focus on "transformative" potential of social inclusion is also helpful in redefining an idea of mutuality of inclusion, or what Parekh (2006) calls a "dialogical form" of integration. The social inclusion model recognises that belonging and identity can be seen as mutually interactive phenomena that are both socially managed and personally negotiated (Caxaj \& Berman, 2010). While many studies have centred on the management of migration and migrants, this article draws attention to the individuals' active role in negotiating, interpreting and appropriating the conditions of social inclusion. Accounting for the multidimensional and multilayered nature of social inclusion, the paper highlighted the heuristic role of social engagement in fostering the feelings of belonging and personal growth for migrant youth. 


\section{Acknowledgements}

This paper is based on an Australian Research Council Linkage Grant which included two important industry partners, namely the Centre for Multicultural Youth and the Australian Red Cross. The authors would like to express their deep gratitude to project co-investigator Zlatko Skrbiš as well as project researchers Maša Mikola, Libby Effeney, Melinda Chiment, Ameera Karimshah and our industry partners Steven Francis, Carmel Guerra, and Soo-Lin Quek for their valuable contributions in organising data collection activities, conducting interviews and performing initial compilation of research data.

\section{Conflict of Interests}

The authors declare no conflict of interests.

\section{References}

Bennett, W. L. (2003). Civic Learning in Changing Democracies: Challenges for Citizenship and Civic Education. Working Paper No. 4. Washington: Center for Communication and Civic Engagement, University of Washington.

Bourdieu, P. (1986). The Forms of Capital. In J. Richardson (Ed.), Handbook of Theory and Research for the Sociology of Education (pp. 241-258). New York: Greenwood.

Caxaj, C.S., \& Berman, H. (2010). Belonging among newcomer youths: Intersecting experiences of inclusion and exclusion. Advances in Nursing Science, 33(4), 17-30.

Coleman, J. (1988). Social capital in the creation of human capital. American Journal of Sociology, 94, 95120.

Colic-Peisker, V. (2005). At least you're the right colour: Identity and social inclusion of Bosnian refugees in Australia. Journal of Ethnic and Migration Studies, 31(4), 615-638.

Fangen, K. (2010). Social exclusion and inclusion of young immigrants: Presentation of analytical framework. Young, 18(2), 133-156.

Freiler, C. (2002). The Context for Social Inclusion. Toronto: Laidlaw Foundation.

Gray, M., \& Hayes, A. (2008). Social inclusion: A policy platform for those who live particularly challenged lives. Family Matters, 78, 4-7.

Hagan, J. M. (1998). Social networks, gender, and immigrant incorporation: Resources and constraints. American Sociological Review, 63(1), 55-67.

Hanvey, L. (2003). Social Inclusion Research in Canada: Children and Youth. In Social Inclusion Research Conference. Ottawa: Canadian Council on Social Development.

Hardwick, S. (2003). Migration, embedded networks and social capital: Towards theorizing North American ethnic geography. International Journal of Population Geography, 9, 163-179.

Harris, A. (2013). Young People and Everyday Multiculturalism. New York: Routledge.

Hedetoft, U. R. (2013). Social Inclusion: Inaugural editorial. Social Inclusion, 1(1), 1-2.

Hunter, B. (2009). Indigenous social exclusion: Insights and challenges for the concept of social inclusion. Family Matters, 82, 52-61.

Kroger, J. (2004). Identity in Adolescence: The Balance between Self and Other (3rd ed.). New York: Routledge.

Levitas, R. (2003). The Idea of Social Inclusion. In Social Inclusion Research Conference. Ottawa: Canadian Council on Social Development.

Mansouri, F., \& Lobo, M. (2011). Introduction: Social Inclusion: Exploring the Concept. In F. Mansouri \& M. Lobo (Eds.), Migration, Citizenship and Intercultural Relations (pp. 1-12). UK: Ashgate.

Modood, T. (2013). Multiculturalism: A Civic Idea. Cambridge: Polity.

Parekh, B. (2006). Europe, Liberalism and the "Muslim question". In T. Modood, A. Triandafyllidou, \& R. Zapata-Barrero (Eds.), Multiculturalism, Muslims and Citizenship (pp. 179-203). Routledge: London and New York.

Portes, A. (1998). Social capital: Its origins and applications in modern sociology. Annual Review of Sociology, 24, 1-24.

Portes, A. (2000). The two meanings of social capital. Sociological Forum, 15, 1-12.

Putnam, R. D. (1993). Making Democracy Work: Civic Traditions in Modern Italy. Princeton, NJ: Princeton University Press.

Putnam, R. D. (2000). Bowling Alone: The Collapse and Revival of American Community. New York: Simon \& Schuster.

Putnam, R. D. (2007). En pluribus unum: Diversity and community in the twenty-first century. Scandinavian Political Studies, 30(2), 137-174.

Room, G. (Ed.) (2004). Beyond the Threshold: The Measurement and Analysis of Social Exclusion. Bristol: Policy Press.

Saunders, P. (2005). The Poverty Wars. Sydney: University of New South Wales.

Tilly, C. (2007). Trust networks in transnational migration. Sociological Forum, 22(1), 3-24.

Triandafyllidou, A., Modood, T., \& Zapata-Barrero, R. (2006). European Challenges to Multicultural Citizenship. In T. Modood, A. Triandafyllidou, \& R. Zapata-Barrero (Eds.), Multiculturalism, Muslims and Citizenship (pp. 1-22). London and New York: Routledge.

Vyncke, V., De Clercq, B., Stevens, V., Costongs, C., Barbareschi, G., Hrafn Jónsson, S., Darias Curvo, S., Kebza, V., Currie, C., \& Maes, L. (2013). Does neigh- 
bourhood social capital aid in levelling the social gradient in the health and well-being of children and adolescents? A literature review. BMC Public Health, 13(1), 1-18.
Woolcock, M. (1998). Social capital and economic development: Toward a theoretical synthesis and policy framework. Theory and Society, 27(2), 151-208.

\section{About the Authors}

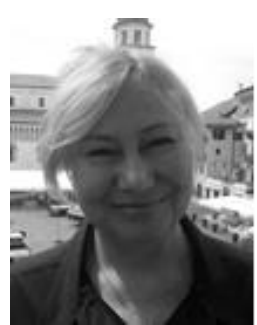

\section{Dr. Liudmila Kirpitchenko}

Dr. Liudmila Kirpitchenko is a sociologist with research interests in intercultural encounters, skilled migration, academic mobility, internationalisation of education, cosmopolitanism and research methodology. She authored a book Academic Mobility and Intercultural Dialogue: Eastern European Migrants in Australia, Canada and Italy (2011) and co-edited Insider Research on Migration and Mobility: International Perspectives on Researcher Positioning (2014). Currently, Dr. Kirpitchenko is a Visiting Postdoctoral Fellow at the European University Institute in Florence, Italy.

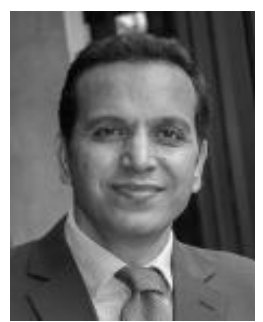

\section{Dr. Fethi Mansouri}

Alfred Deakin Professor Fethi Mansouri holds a UNESCO Chair in comparative research on cultural diversity and social justice, and is the Director of the strategic research Centre for Citizenship and Globalisation at Deakin University, Australia. He is the editor of the Journal of Intercultural Studies (Routledge) and a global expert advisor to the United Nations (Alliance of Civilizations). Professor Mansouri's 2004 book Lives in Limbo: Voices of Refugees under Temporary Protection was short-listed for the 2004 Human Rights Medals and Awards. 